Adam Bonica ${ }^{a, *}$

\title{
Avenues of influence: on the political expenditures of corporations and their directors and executives
}

DOI 10.1515/bap-2016-0004

Previously published online November 7, 2016

Abstract: The literature on corporate political influence has primarily focused on expenditures made by corporations and their PACs but has largely ignored the political activities of the individuals who lead these firms. To better understand the role of corporate elites in political advocacy, I introduce a new database of campaign contributions made by corporate directors and executives of Fortune 500 firms. Donating to political campaigns is nearly universal among corporate elites. When compared to corporate PACs, corporate elites are more ideological, more willing to support non-incumbents, and less likely to target powerful legislators. The results also reveal substantial heterogeneity in the political preferences of directors both across and within firms. In addition to challenging widely held beliefs about the political leanings of corporate elites, the prevalence of bipartisan boardrooms has important implications for how the preferences of key decision-makers within a firm shape its political activities.

\section{Introduction}

In the wake of the Supreme Court's 2010 ruling in Citizens United v. Federal Election Commission (558 US 310 [2010]), dire warnings rang out that the decision would herald a new era in politics by opening the floodgates for billions of dollars in corporate political expenditures. Several years later there is little evidence that these predictions have come to pass. The anticipated flood of corporate political cash has amounted to no more than a trickle. In the 2012 election cycle, a handful of predominantly privately owned corporations spent roughly $\$ 75$ million from their treasuries on federal elections, or roughly one percent of the estimated $\$ 6$ billion spent in total for the election cycle. Even if one were to entertain the heroic assumption that all "dark money" funneled through non-disclosing 501(c)

aReplication data is available for download at http://dx.doi.org/10.7910/DVN/6R1HAS.

*Corresponding author: Adam Bonica, Assistant Professor, Department of Political Science, Stanford University, Encina Hall West, 616 Serra Street, Room 307, Stanford, CA 94305-6044, USA, e-mail: bonica@stanford.edu 
non-profit organizations originated from corporate treasuries, corporations could account for at most another \$318 million, still a far cry from the anticipated amounts. Putting aside the serious discussion to be had about the normative and legal implications of recent court rulings on campaign finance, they appear to have had no practical effect on how corporations engage in politics.

Given the value of the public policies at stake and the vital role of money in US elections, it makes sense that corporations would want to leverage their considerable resources to influence the outcomes of elections in their favor. Why, then, did the tidal wave of corporate cash fail to materialize? Were corporations apprehensive about the prospect of an already risky investment rife with liability? Were they unable to overcome collective action and coordination problems associated with mobilizing members to support shared political causes? Or did commentators simply misjudge the importance corporate political strategies have placed on influencing the outcomes of elections?

This paper helps place the response to Citizens United in perspective by offering a comprehensive accounting of corporate political expenditures. I consider three general avenues of political influence open to corporations: (1) spending to support candidates through their PACs and independent expenditures; (2) lobbying activities; and (3) the efforts of corporate directors and executives. Consistent with earlier findings, I find that the attention given to corporate influence in elections is far in excess of its actual importance. The amounts spent on campaigns and how few of these campaign dollars flow toward competitive races are inconsistent with the notion that corporations are eager and willing to invest in electoral politics. Instead, corporate lobbying expenditures have historically eclipsed PAC contributions by ratios of more than ten to one, suggesting that corporations are more concerned with influencing the legislative process than the outcomes of elections.

Despite an abundance of research on the determinants of corporate PAC contributions and the growing literature on corporate lobbying expenditures, relatively few studies have addressed the political activities of the executives and directors charged with managing and governing these firms. Although there is strong, although conditional, support for the claim that corporate PAC contributions are a form of political investment, ${ }^{1}$ much less is known about the giving behavior of individuals affiliated with these firms or how this compares to other types of donors. Do corporate elites contribute to further the same goals and objectives as their parent corporations? Or do they give as concerned citizens guided by their personal beliefs about what policies are in the best interests of

1 Snyder (1990). 
the nation? In other words, are corporate donors giving to advance their interests or ideology?

Understanding why corporate elites engage in politics and with what purpose is essential for making sense of corporate political influence. Any theory of firmlevel political strategies is incomplete without accounting for the political preferences, objectives, and strategies of those in leadership positions within these firms. This paper aims to help fill this gap in the literature by utilizing a new database on contributions by corporate directors and CEOs from Fortune 500 firms. The prevailing view, and one that dominates the literature on the subject, is that corporate elites adopt strategies designed to promote their personal economic interests or those of their firms. I find that contributions made by corporate elites serve a very different purpose than what is typically assumed. By and large, corporate elites give in a manner consistent with advancing their personal ideological preferences. Insofar as they engage in access-seeking behavior, they typically continue to prioritize partisanship and ideology over legislative clout.

I further consider the relationship between individual-level preferences and the political activity of firms. A comprehensive mapping of the ideological preferences of corporate elites reveals a high-degree of ideological heterogeneity both within and across firms. Combined with evidence that corporate elites are nearly as ideological as other individual contributors, I argue that increased ideological diversity among a firm's executives and directors presents a barrier to engaging the firm in certain types of political activities. The characteristically cautious and uncontroversial approach to spending on politics shared by many corporations may be driven more by pressures internal to the firm than by external pressures, such as the fear of political retribution. This has important implications for why corporations have refrained from spending large sums on elections following Citizens United and, more generally, for explaining how corporate influence operates in the political arena.

\section{Corporate political spending in perspective}

Political spending patterns can reveal a great deal about a corporation's priorities and strategies for achieving its objectives. For example, if corporations were primarily interested in influencing the outcomes of elections by bolstering the electoral prospects of their preferred candidates, one would anticipate that money would flow to campaign coffers of candidates in competitive races and to outside spending groups. In contrast, spending disproportionately on lobbying suggests a different strategy aimed at influencing legislation as it is being crafted and voted on. Nonetheless, spending patterns should be understood in 
the context of the rules and regulations that govern political activity and the restrictions they impose on certain types of expenditures.

Much of literature on corporate political influence has focused on the role of quid pro quo transactions between legislators and interest groups in organizing the market for campaign contributions. This perspective, which is known as the investor model, traces back to the seminal work of Denzau and Munger (1986) who developed a theoretical explanation for contributions as payments in a market for legislative services, votes, and access. A key implication of this model is that imposing legal limits on the size of contributions will price most services out of the market. Milyo, Primo and Groseclose (2000) summarize the dilemma as follows:

Simply put, PAC contributions are not the only route by which interested money might influence policy makers and, given existing limits on the size of PAC contributions, neither are they the most likely route. The very idea of building a majority coalition by buying off individual members of Congress (a group not renowned for their fidelity or trustworthiness) with small campaign contributions and without an explicit contracting mechanism, as all the while competing interests work at counter purposes, sounds something akin to herding cats.

The apparent implausibility of campaign contributions acting as transactions in a spot market for votes and legislative favors suggests that the attention given to PAC contributions as a vehicle for political influence is largely misplaced. Indeed, insofar as corporate PACs contributions serve as a form of investment, they are best understood as a tool for securing access to legislators. ${ }^{2}$ In other words, corporate PAC contributions may be thought of as little more than very expensive, very targeted advertising buys intended to support a firm's lobbying operations.

In permitting corporations to spend in unlimited amounts to advocate on behalf or against a candidate, thereby unshackling corporations from their PACs, Citizens United would seem to have eliminated the main barrier to engaging in quid pro quo behavior. Citizens United was met with concerns that many of the favors and services that had been priced out of reach would now be up for sale to the highest bidder - an argument that featured prominently in Justice Steven's dissenting opinion. An equally valid set of concerns were raised about the potential for increased corporate influence in elections if corporations started spending heavily to help secure seats for candidates sympathetic to their concerns.

Yet despite the reasonableness of these concerns, the notion that corporations have taken advantage of their new-found freedoms following Citizens United is not well founded. In 2010, a mere \$15 million was spent by a handful of corporations

2 Hall and Wayman (1990); Langbein (1986). 
on independent expenditures directed at federal elections, amounting to approximately 0.2 percent of total corporate political expenditures. The total amount spent by corporations increased to $\$ 75$ million during the 2012 election cycle. However, nearly $\$ 20$ million was attributable to the emergence of shell corporations used by individuals, who were presumably concerned about privacy, to cloak their donations. In lieu of hard evidence of corporate funding of independent expenditures, reform-minded citizens and organizations have typically pointed to the prevalence of "dark money" funneled through 501(c)'s as a potential conduit of corporate expenditures. To assess this claim, I calculated a theoretical upper bound on corporate dark money in recent election cycles assuming that all money spent by 501(c) organizations originated from corporate treasuries. Even under this heroic assumption, at most \$322.3 million was given through dark money channels in 2012. The actual amount originating from corporate treasuries is likely a fraction of this total. (See Supplementary material A for details.)

Figure 1 summarizes the amounts spent by corporations on various political activities during the 2004 through 2010 election cycles. Spending on elections represents only a small fraction of total expenditures. Lobbying expenditures consistently dominate. For instance, during the 2010 election cycle, $\$ 3.64$ billion was spent on federal elections versus $\$ 7.5$ billion spent on lobbying. Of these totals, corporations accounted for at least 68 percent ( $\$ 5.18$ billion) of the federal lobbying expenditures but only about 7 percent ( $\$ 246$ million) of federal campaign expenditures, most of which was directed at safe incumbents with little or no chance of losing their seat. The amounts spent on a select group of ballot measures demonstrates that corporations are willing to spend large sums to influence election outcomes if an issue of concern to them is at stake - but only, it seems, when candidates and parties are not directly involved.

The disproportionate share of corporate political expenditures spent on lobbying is not a new discovery. These patterns were first documented by Milyo, Primo, and Groseclose (2000) shortly after disclosure laws made lobbying expenditures available and were later elaborated on by Ansolabehere, de Figueiredo, and Snyder (2003). This observation also comports with more recent findings that returns on lobbying are far greater (and more easily observed) than the expected returns from spending on elections. ${ }^{3,4}$

3 de Figueiredo and Silverman (2006).

4 The preference for spending on lobbying over electioneering is also apparent in spending patterns of the US Chamber of Commerce. The Chamber, which is widely viewed as a de facto political arm of the business community, spent a combined total of $\$ 33$ million on PAC contributions and independent expenditures compared with a total with $\$ 302$ million on lobbying during the 2009-2010 election cycles. 


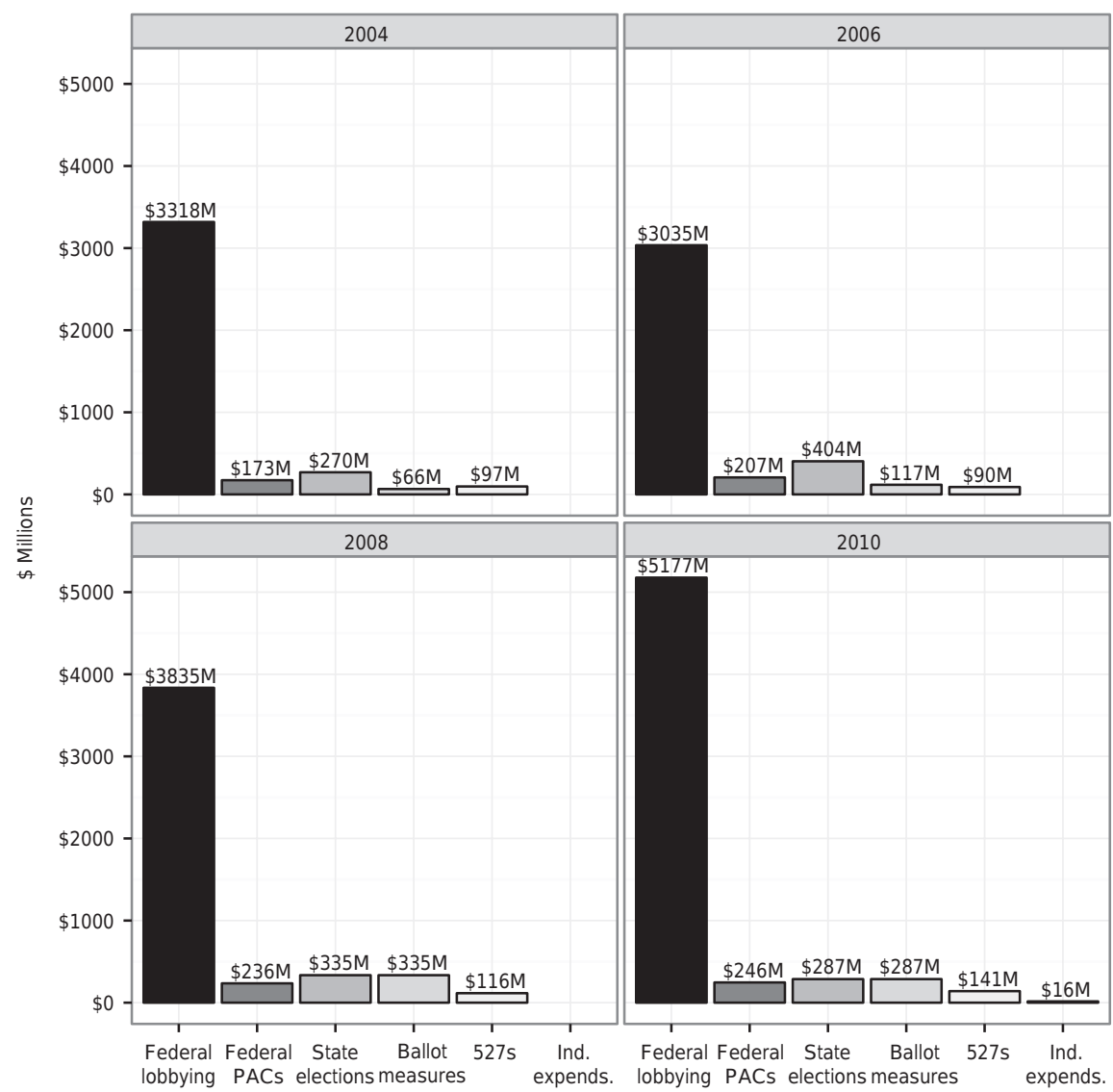

Figure 1: Allocation of corporate political expenditures.

Sources: For lobbying data, the Center for Responsive Politics. For data on 527's, the Internal Revenue Service. For data on federal PACs, state elections, and ballot measures, Database on Ideology, Money and Elections (DIME).

It is worth noting that patterns of corporate political expenditures are in stark contrast to organized labor. During the 2012 election cycle, labor unions spent $\$ 105$ million on independent expenditures, more than the $\$ 60$ million labor PACs spent on federal elections or the $\$ 96$ million spent on federal lobbying efforts. The types of unlimited spending made possible by Citizens United now account for 40 percent of what organized labor spends at the federal level compared to a mere one percent of what corporations spend. On this basis alone, it appears that unions, not corporations, had been more constrained by the ban on spending in place prior to Citizens United. 


\section{Why is there so little corporate cash in elections?}

Decades ago, Tullock (1972) famously asked why there is so little money in politics? Given the emphasis on lobbying expenditures in the observed patterns of political expenditures, a refinement of Tullock's puzzle might instead ask why corporations spend so little to influence the outcomes of elections?

One explanation is that regulation of corporate political activity has been the main limiting factor. However, if this were the case, Citizens United should have resulted in a sharp increase in corporate political expenditures, which it did not.

Another explanation is that corporations avoided what they deemed to be risky investments with the potential to backlash in the form of investor unrest, a public relations nightmare, or worse, a consumer boycott. ${ }^{5}$ Yet this fails to explain what deterred firms that are largely insulated from the threat of consumer boycotts, and more curiously, why corporations fearful of repercussions did not simply channel large sums of money through non-disclosing 501(c) organizations.

Alternatively, spending on elections might be an objectively poor investment. It is plausible that the marginal returns could be so low that the standard strategy that combines lobbying operations with a steady flow of corporate PAC contributions strictly dominates spending aggressively to elect friendly candidates. In addition to undermining Tullock's main premise, this would seemingly call into question why any donor - including labor unions, privately-held corporations, and wealthy individuals - would ever spend on independent expenditures.

A fourth and novel explanation is that the corporate community faced unforeseen coordination and collective action problems both within and across firms. The collective action problems associated with mobilizing corporations with shared interests to volunteer funds for political causes, particularly those arising from free-riding, are widely recognized. ${ }^{6}$ Less appreciated is the potential coordination problem that influential actors within a firm face when deciding on which candidates to support and which to oppose. In giving generously to members of both parties, and by virtue of their reliance on voluntary contributions from a firm's managers and investors, corporate PACs have largely avoided these

5 Target Corp. learned this lesson the hard way shortly after the ruling in Citizens United when a $\$ 150,000$ donation to a group backing then Republican gubernatorial candidate for Minnesota Tom Emmer incited a media firestorm and an ensuing nationwide consumer boycott. Target's cautionary tale would seem more than sufficient to give pause to any brand-conscious corporation looking to donate publicly to political causes.

6 Busch and Reinhardt (2000). 
coordination problems; whereas, the all-in and hyper-partisan nature of outside spending would seem to greatly exacerbate them. High levels of ideological diversity among directors and executives within the typical firm, and the naturally conflicting opinions about which policies are best for the country and/or their firm, might make it difficult to reach a political consensus.

The fourth explanation is essentially an argument that preference aggregation could have a moderating influence on corporate political activity. For it to be generally plausible, the following conditions should hold: (1) corporate elites have personal political preferences that exist independently of their firms interests, (2) corporate elites are more than agents acting directly on behalf of their firms, and (3) ideological heterogeneity is a common feature among firms. In what follows, I consider evidence for each of the above.

\section{Political spending by corporate elites}

Although numerous scholars have addressed agency capture and the revolving door between corporations and the public sector, only recently has much attention been given to the role corporate elites have in financing campaigns and advocating on behalf of their firms. One line of inquiry has considered whether corporate executives have special incentives to make political contributions. Gordon, Hafer, and Landa (2007) identify a robust relationship between political giving and the sensitivity of compensation to company performance. Fremeth, Schaufele, and Richter (2013) similarly find that being promoted to CEO of a S\&P 500 company is associated with an increase in the total amount donated beyond what would be expected from increased earnings alone. ${ }^{7}$ Although these studies identify conditions that lead executives to spend more on politics, none directly considers whether these same incentives also influence decisions about how to allocate their funds.

Perhaps the greatest barrier to studying the contribution behavior of individual donors has been tracking their giving across time and levels of government. The Federal Election Commission (FEC) assigns unique committee identifiers for PACs that can be used to track their giving but does not do the same for individual donors. To further complicate matters, each state is responsible for disclosing contributions to state elections and does so independent of the FEC. To address

7 Another line of research uses contributions by CEOs to explain outcomes of interest such as firm performance Ovtchinnikov and Pantaleoni (2012) and corporate social responsibility Chin, Hambrick, and Treviño (2013). 
these issues, I utilize the Database on Ideology, Money in Politics, and Elections (DIME). ${ }^{8}$ The database currently encompasses over 100 million contributions made by individuals and organizations to local, state, and federal elections between 1979 and 2012. The particular advantage bestowed by the DIME database is that identity resolution methods have been used to assign unique identifiers for all individual donors, thus making it possible to track their giving across time and levels of government. ${ }^{9}$

The analysis here focuses on the contribution behavior of board members and CEOs of Fortune 500 companies. In doing so, I depart from most previous studies which have generally focused exclusively on political contributions made by CEOs. The dataset of corporate elites was constructed by linking publicly available information on executives and board memberships against the database of contribution records using automated record-linkage methods. This task was aided by research assistants who supervised the record-linkage process by hand-checking each set of matched records to ensure that all contributions made by Fortune 500 donors were correctly assigned. Of the 4493 CEOs and directors serving as of July 2012, 3736 were successfully matched against DIME, thus identifying them as political donors.

The phenomenally high rates of giving among corporate elites provides a rich data source to examine why and how they give. Over 83 percent of corporate elites in the sample have made political contributions. Of those who have not contributed, many are foreign nationals and are prohibited by law from doing so. Overall, the sample has given a total of $\$ 852$ million between 1979 and 2012. Of those who have contributed, they have given a lifetime average of $\$ 197,435$ and a lifetime median of $\$ 37,800$ per individual. ${ }^{10}$ To help place these amounts in perspective, the $\$ 213$ million given by the sample to state and federal elections in 2012 is comparable to the $\$ 302$ million total contributed by all 1538 corporate PACs that were active during the same election cycle.

Although those in the sample hail from the nation's largest and most powerful firms, they still represent a small percentage of the population of corporate elites. When one searches the database for individuals listing a variant of corporate executive as their occupation (e.g. executive or CEO), the total amounts contributed soar to well over a billion dollars in each of the past few election cycles.

\footnotetext{
8 Bonica (2013a).

9 See http://data.stanford.edu/dime for details on the database and its construction.

10 These totals exclude contributions made by their spouses or family members. Also excluded is an additional $\$ 153$ million spent self-financing personal campaigns for political office.
} 


\section{Partisans or profiteers?}

The amounts contributed by corporate elites highlights their role in corporate political activity. To what extent is their giving guided by their personal ideology versus the interests of their firms? This question was first considered by Burris (2001). He recognized the dual-roles faced by corporate elites who are at once individual citizens and representatives of their firms. In examining a sample of CEOs who had donated during the 1980 election cycle, he provided initial evidence that CEOs approach political giving differently than do corporate PACs. In revisiting this question, the much richer data on contributions and time-varying candidate characteristics as well as newly developed methodological tools allow for a more detailed and rigorous analysis of the giving behavior of corporate elites.

I first examine whether contributions from corporate elites are more likely to flow to candidates who go on to win. I then examine the levels of partisan consistency across time in the contribution patterns of corporate elites. To obtain more general results, I empirically test competing models of giving across several types of donors. This is followed by an overview of the ideological leanings of corporate elites both within and across firms.

\subsection{Picking winners}

More so than any other candidate trait, investor models consistently predict that contributions from savvy investors should go disproportionately to the candidates that are most likely to win. This conforms with a simple arbitrage pricing model where contributions are pegged to the odds the candidate will win office. ${ }^{11}$ As such, the percentages of dollars given to winning candidates by each group of donors presents a natural starting point for the analysis.

Figure 2 compares the percentages of contribution dollars given to successful candidates for the House and Senate by corporate PACs, registered lobbyists, corporate elites, the general population of itemized individual donors, and small donors giving in unitemized amounts. As a group, corporate PACs consistently give a much larger percentage of their funds to candidates that go on to win than does any group of individual donors. The figure also reveals systematic differences in the propensity to support successful candidates across types of individual donors. Small donors consistently give the lowest percentage of their contributions to winning candidates, hovering around 50 percent in recent election

11 Snyder (1990); Welch (1980). 


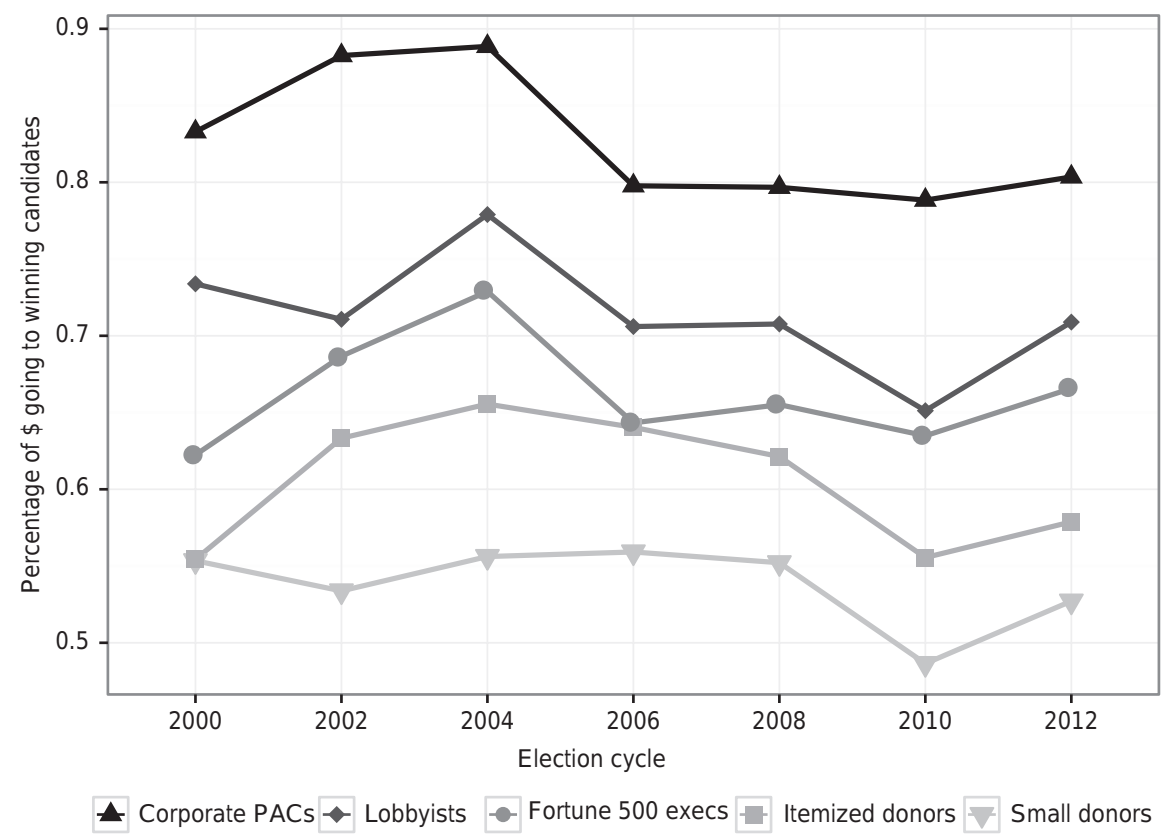

Figure 2: Percentages of funds given to winning candidates.

Source: Database on Ideology, Money in Politics and Elections.

Note: The percentages are based on all contributions made to congressional candidates aggregating across donors from each group. Contributions to presidential candidates are excluded.

cycles. Itemized individual donors are somewhat better at picking winners, who are in turn slightly outdone by corporate elites. Interestingly, the percentages of contribution dollars from corporate elites going to winners approaches that of registered lobbyists, particularly in the cycles where Republicans performed well in congressional elections.

On the one hand, this suggests that corporate elites are more likely than other individual donors to engage in access-seeking behavior. However, it could also be a function of the heightened viability of candidates likely to emerge from corporate social and professional networks, coordination with lobbying efforts of the firm or industry, or a general preference for established candidates and moderates. Moreover, unlike corporate PACs and lobbyists which give only a small fraction of their funds to presidential candidates, corporate elites typically give a large percentage of their contributions to presidential candidates. When contributions made to presidential candidates are included, the percentage of dollars given to winning candidates by Fortune 500 donors falls precipitously to just 0.46 in 2008 and 0.38 in 2012, reflecting the general preference for Republican presidential candidates. 


\subsection{Hedging bets}

A pattern of giving often conjectured is that strategic donors will hedge their bets by donating to both sides of given race. The suggested rationale for giving to opposing candidates is that when the outcome is uncertain, interested donors may wish to signal their support and willingness to work with both candidates so as to avoid siding with the loser and, as a result, risk being denied access to the eventual winner. While some have questioned the general viability of such a strategy, if successful it could secure access to both sides during the campaign as well as to the winning candidate after the election. A finding that hedging behavior is prevalent among executives would be extremely difficult to reconcile with ideological models of political giving that hold at their core that contributors give in order to advantage one type of candidate over another.

I examine whether hedging is prevalent by calculating the number of Fortune 500 donors that gave to the presidential nominees of both parties, which can then be compared to the number that gave to one of the two candidates. Table 1 reports the results for each of the past four presidential elections. Although hedging behavior is far from nonexistent, only a small fraction of donors give to both presidential candidates in a given election cycle. In the most recent presidential election cycle, only three percent of the corporate elites who gave to a presidential candidate gave to both Barack Obama and Mitt Romney. Of those who supported both members, over half signaled a preference by giving at least five times more to one candidate than the other. It is worth noting that high-profile presidential elections are where we should most expect hedging to occur. When the analysis is extended to include all congressional races between 1980 and 2012 in which both major parties fielded candidates in the general elections, the results show that corporate elites gave to both sides in only one percent of cases.

Table 1: Numbers of Fortune 500 directors and executives contributing to presidential nominees.

\begin{tabular}{lrrr}
\hline Election & Gave to dem. nominee & Gave to rep. nominee & Gave to both \\
\hline 2000 & 256 & 814 & 53 \\
2004 & 392 & 1027 & 82 \\
2008 & 724 & 830 & 114 \\
2012 & 384 & 1081 & 43 \\
\hline
\end{tabular}

Source: Database on Ideology, Money in Politics and Elections.

The first two columns report the number of Fortune 500 directors and executives that gave exclusively to the presidential candidate nominated by each party to run in the general election. The third column reports the number that made contributions to both candidates. 


\subsection{Consistency in partisan giving}

Further evidence that corporate elites and corporate PACs give with different goals in mind is had by examining consistency in partisan giving rates across election cycles. In theory, those seeking to maximize their return on investment would adjust which candidates they support in response to changes in institutional power or partisan balance in the legislature. In particular, we should expect partisan giving rates to shift either in anticipation of, or in response to, changes in partisan control of the chamber. ${ }^{12}$

As a group, corporate elites exhibit high levels of ideological consistency. Figure 3 examines partisan consistency in giving across all candidates. It displays the levels of ideological consistency in giving patterns of corporate elites, corporate PACs, and the general population of donors. It does so by first categorizing donors into one of ten categories based on the Republican share of major party contributions in previous election cycles and then plotting a bar chart that shows the total amounts given to Democrats and Republicans from each category. For example, the leftmost bar labeled " $<10 \%$ " in the plot of itemized donors in 2012 displays the partisan breakdown of contribution amounts for donors who had given at least 90 percent of their contributions dollars to Democrats in previous cycles. It shows that 94.4 percent of contribution dollars from donors that leaned heavily Democratic in the past again went to Democratic recipients in 2012.

Figure 3 reveals stark differences in the patterns of giving by individual donors and corporate PACs. A point of interest is the prevalence of campaign dollars originating from strong partisans who in the past had given at least 90 percent of their funds to a single party. This contrasts with the distributions for corporate PACs which predominantly fall within the middle categories. In terms of the proportions of strong partisans and the levels of consistency in partisan giving across election cycles, corporate elites look much more like other individual donors than they do corporate PACs. In a typical election cycle, well over three-fourths of funds from corporate elites originate from strong partisans versus just 2-3 percent for corporate PACs. ${ }^{13}$

Corporate PACs are much more sensitive than individual donors to changes in majority party control. Corporate PACs, which had given 65 percent of their funds to

12 Bonica (2013b); Cox and Magar (1999).

13 This is also seen in the infrequency with which corporate elites support one party's presidential nominee in one election cycle and defect to support the other party's nominee in the following election cycle. Only 19 out of 951 Fortune 500 donors that gave exclusively to Obama in 2008 switched sides in 2012 and gave exclusively to Romney. A total of five donors exhibited the opposite pattern, defecting from McCain in 2008 to Obama in 2012. 

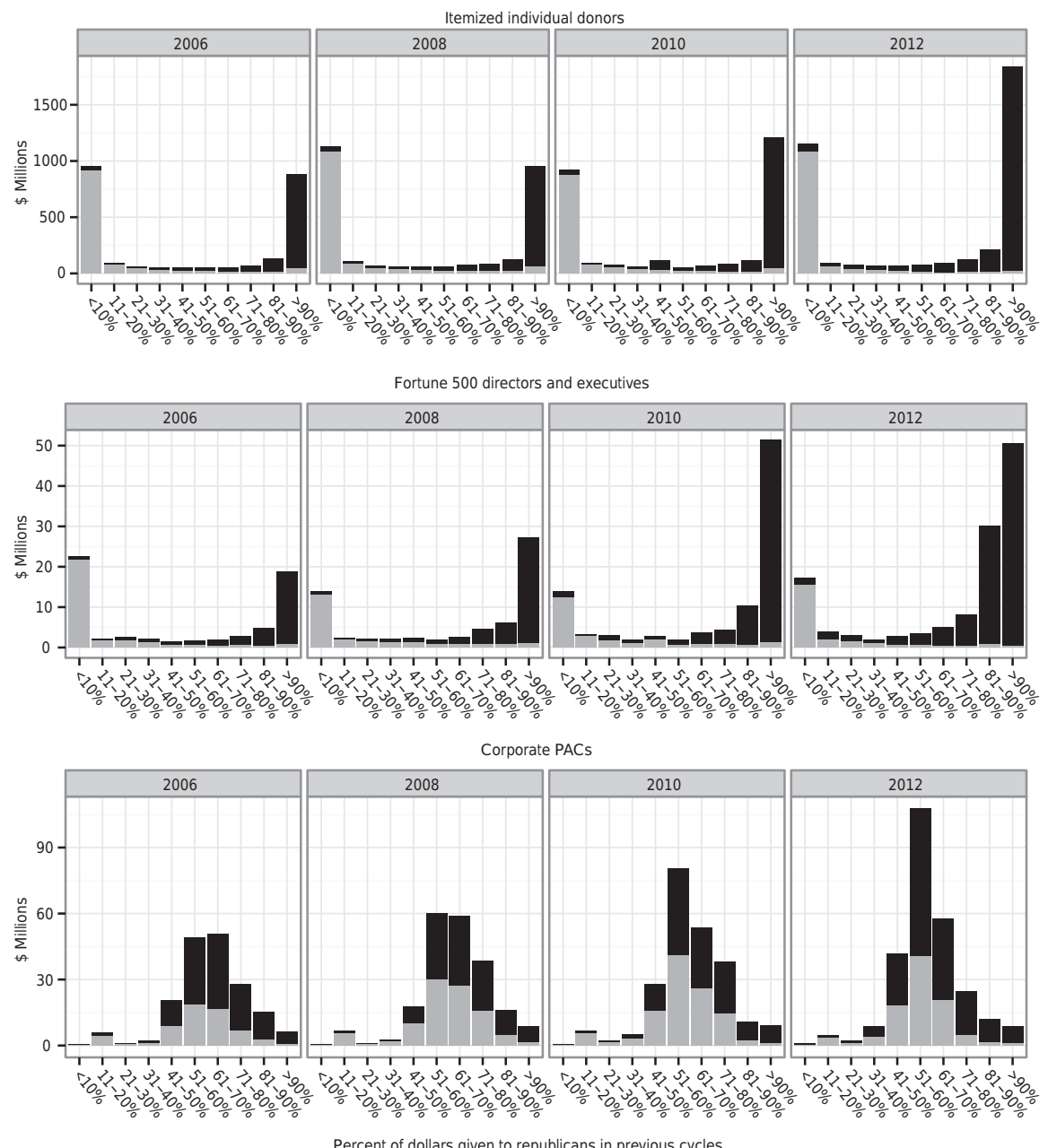

Figure 3: Partisan giving rates and past giving.

Source: Database on Ideology, Money in Politics and Elections.

Note: Past contributions are shaded by the party of the recipient. Total past contributions to Republicans are shown in black and total past contribution to Democrats are shown in gray. The rightmost bars in the plots of Fortune 500 executives were truncated at $\$ 50$ Million in 2010 and 2012 to enhance readability. The actual amounts given to Republicans by donors in this category were \$181 million in 2010 and \$121 million in 2012.

members of the Republican majority during the 2005-2006 election cycle, shifted their giving in response to the Democrats regaining both chambers by splitting their contributions roughly evenly between the parties in each of the following two election cycles. In contrast to the premium placed on majority status by corporate 
PACs, corporate elites give more when their preferred party is out of power. They gave just 46 percent and 48 percent of their total contributions to Republicans in the 2003-2004 and 2005-2006 election cycles, respectively, corresponding to the period of unified Republican control. Yet their contributions to Republicans grew to 61 percent of the total in 2008 and to 91 percent in 2010 on a wave of large contributions to outside spending groups supporting Republicans, who at the time were fighting to regain the majority. This again supports the hypothesis that corporate elites and corporate PACs have different approaches to financing campaigns.

\subsection{Empirically testing competing models of giving}

To obtain more general results, I assess the ideological and investment models in terms of goodness-of-fit across different types of donors. To facilitate the comparisons, I fit a reduced-form version of the item response theory (IRT) that simultaneously controls for ideology and non-spatial candidate characteristics. ${ }^{14}$

After collapsing contribution amounts into count values that range from 0 to $10,{ }^{15}$ the following right-censored negative binomial model is estimated independently for each individual:

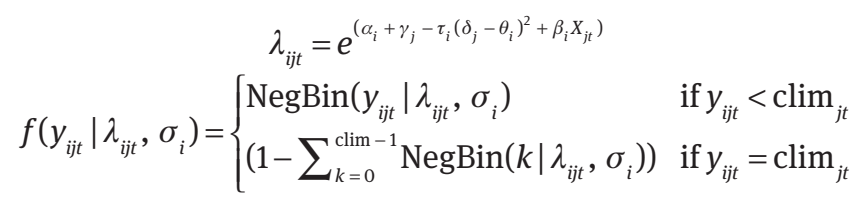

where $y_{i j t}$ is the amount contributed to candidate $j$ in period $t$; $\operatorname{clim}_{j t}$ is the maximum allowable limit on contributions to candidate $j$ in period $t$, taking on the value of 5 for candidates who do not make it past the primary elections and a value of 10 for candidates who continue on to the general elections; $\sigma_{i}$ is a contributor specific over-dispersion parameter; $\theta_{i}$ is the ideal point parameter for contributor $i$; $\delta_{j}$ is the common-space DIME score for candidate $j ;{ }^{16} \alpha_{i}$ and $\gamma_{j}$ are contributor

14 Bonica (2013b).

15 For PACs, I round up to $\$ 1000$ intervals, which reflects the $\$ 10,000$ maximum allowable contribution amount to a candidate over a 2-year election cycle. For individual donors, I round up to $\$ 400$ intervals with any value over $\$ 4000$ taking on the maximum value of 10 , which reflects the maximum allowable contribution amount to a candidate over a 2-year election cycle during the 2004 election cycle. Federal contribution limits for individuals adjust with inflation, increasing to $\$ 5000$ by 2012 . The $\$ 4000$ limit was selected to maintain uniformity.

16 See Bonica (2014) for details. 
and candidate fixed effects, ${ }^{17}$ and $X_{j t}$ is a matrix of time-varying candidate-specific traits associated with increased likelihood of election and institutional power, such as incumbency status, probability of winning, and majority party status.

To be included in the analysis, a contributor needs to have made at least 25 contributions to federal elections between 2004 and 2012. I report aggregate results for four groups of donors: (1) Fortune 500 directors and CEOs, (2) corporate PACs, (3) lobbyists, and (4) a randomly drawn sample $(\mathrm{N}=5000)$ from the set of individual donors who met or exceeded the 25 contribution threshold.

I fit five alternative models separately for each group of donors. The first is the unrestricted model, which controls for both ideological and strategic giving and includes the complete set of candidate characteristics. The second is the ideological model which only considers the distance between the contributor's ideal point and the ideal points of each potential recipient. The third is the investor model, which is restricted to the set of non-spatial covariates. Consistent with theoretical predictions that increased institutional power is associated with increased fundraising, I constrain the coefficients for the non-spatial covariates to be positive. The fourth model is what I term the inverse-investor model. This model constrains the coefficients for the non-spatial covariates to be negative - thus, to improve model fit, donors must act opposite of what the investor model would predict. The fifth is the baseline model, which is restricted to the contributor and candidate fixed effects, $\alpha_{i}$ and $\gamma_{j}$ (See Supplementary material $\mathrm{C}$ for additional details).

Table 2 reports the total log-likelihood aggregating over all contributors as well as values from a deviance residual summary statistic proposed by Cameron

Table 2: Comparison of model fit for ideological and strategic giving.

\begin{tabular}{|c|c|c|c|c|c|c|c|c|}
\hline & \multicolumn{2}{|c|}{ Corporate elites } & \multicolumn{2}{|c|}{ Corporate PACs } & \multicolumn{2}{|c|}{ Lobbyists } & \multicolumn{2}{|c|}{ Individuals } \\
\hline & LogLik & $R_{\text {Dev }}$ & LogLik & $R_{\text {Dev }}$ & LogLik & $R_{\text {Dev }}$ & LogLik & $\boldsymbol{R}_{\text {Dev }}$ \\
\hline Unrestricted model & -277594 & 0.644 & -1319923 & 0.556 & -1042628 & 0.624 & -1077649 & 0.688 \\
\hline Ideological model & -290445 & 0.574 & -1423310 & 0.418 & -1107479 & 0.539 & -1151295 & 0.634 \\
\hline Investor model & -305024 & 0.486 & -1366567 & 0.503 & -1150374 & 0.467 & -1345615 & 0.454 \\
\hline $\begin{array}{l}\text { Inverse-investor } \\
\text { model }\end{array}$ & -308057 & 0.467 & -1473744 & 0.331 & -1199217 & 0.375 & -1326048 & 0.478 \\
\hline Baseline model & -311599 & 0.445 & -1475250 & 0.329 & -1205432 & 0.362 & -1368383 & 0.433 \\
\hline $\mathrm{N}$ & & 786 & & 1193 & & 2734 & & 5000 \\
\hline
\end{tabular}

$R_{\text {Dev }}$ calculates the marginal improvement in log-likelihood of the estimated parameters over the baseline of setting y at its mean: $R_{D e v}=1-\frac{(L L(y)-L L(\lambda))}{(L L(y)-L L(\bar{y}))}$, where $L L($.$) is the log-likelihood$ function.

17 The value of $\gamma_{j}$ is approximated by the log of the mean contribution received by candidate $j$. 
and Windmeijer (1996) to aid in interpreting model fit for model specifications. Figure 4 shows the distribution of estimated coefficient values from the unrestricted model for several of the non-spatial covariates grouped by donor type.
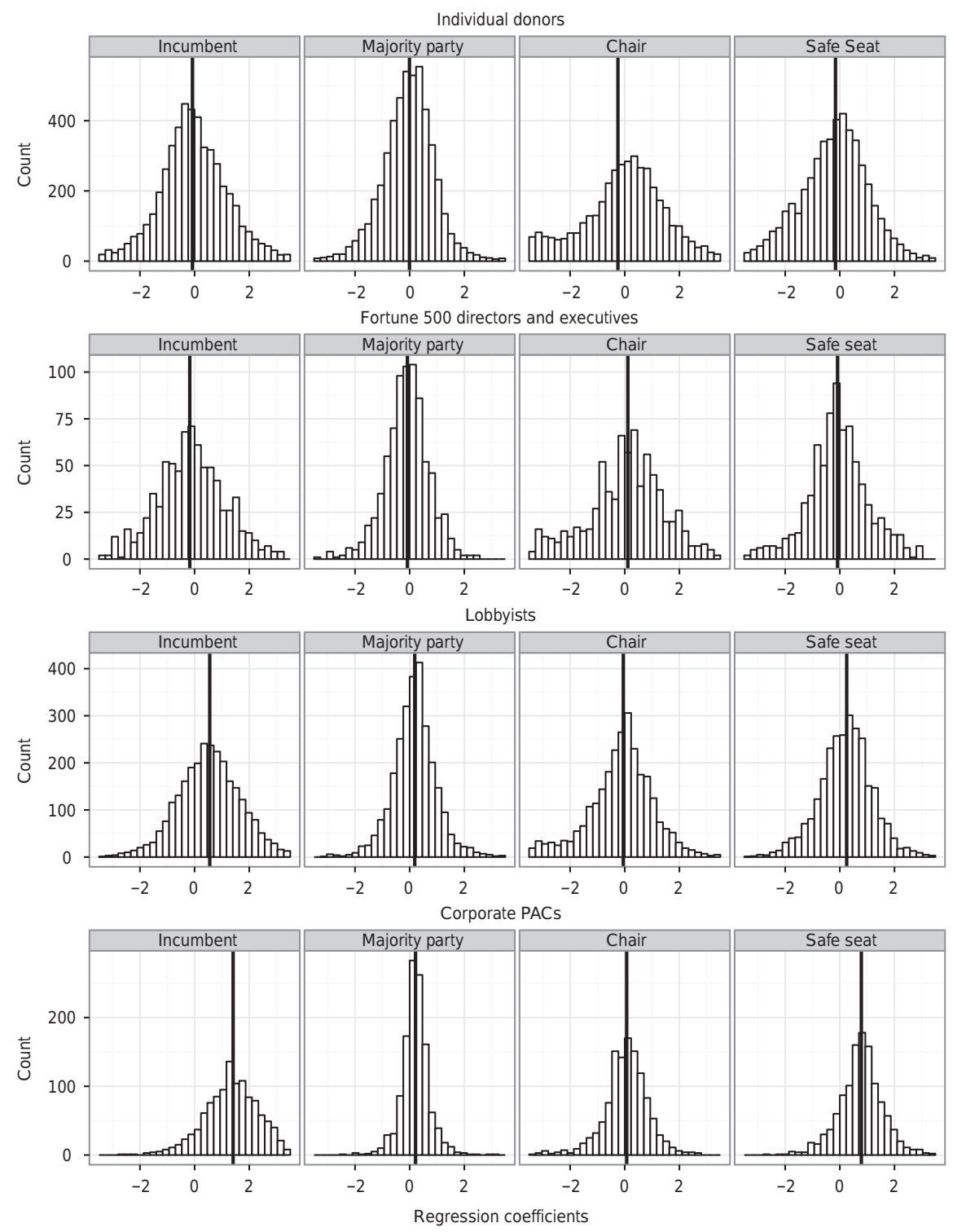

Figure 4: Regression coefficient values for selected variables grouped by donor type. Note: The vertical lines indicate the median value for the regression coefficients for each group. Distributions for the complete set of covariates are found in Supplementary material D. 
The results again place corporate PACs in stark contrast with individual donors. Although corporate PACs condition their giving on ideology, as shown by the substantial improvement in model fit over the baseline model associated with the ideological model, the investor model outperforms the ideological model by a considerable margin. Likewise, the inverse-investor model is associated with a negligible improvement in model fit over the baseline model.

Individual donors exhibit a nearly opposite pattern of behavior. Ideology is a powerful predictor of their contribution decisions, whereas the explanatory power of the investor model is negligible. In fact, the fit associated with the investor model is so poor that the inverse-investor model actually improves fit over it by a small margin.

I test whether observed differences in aggregate model fit also hold at the individual-level using a Vuong test to discriminate between models separately for each donor. For the sample of individual donors, comparing the ideological and investor models indicates that the ideological model is superior in 4223 cases versus just 90 cases where the investor model is superior, with the remaining cases unable to reject the null hypothesis that models are indistinguishable (based on a p-value $<0.05$ ). In comparison, applying the discrimination test for the sample of corporate PACs indicates that the ideological model is superior in 111 cases versus 680 cases for the investor model, with the remaining 402 cases statistically indistinguishable. Corporate elites more closely resemble other individual donors. Not only are they more ideological, they are less likely to give in accordance with the investor model. The Vuong test analysis indicates that the ideological model is superior in 397 cases versus 27 cases for the investor model, with the remaining 366 cases statistically indistinguishable.

The differences across types of donors can be seen more clearly in the distributions of regression coefficients shown in Figure 4. Nearly all corporate PACs have large positive coefficients for Incumbent and Safe Seat. Lobbyists similarly exhibit a general preference for safe incumbents, which is consistent with accessseeking behavior. ${ }^{18}$ In contrast, the median corporate elite actually has negative coefficient values for these covariates, suggesting a slight preference overall for non-incumbents and members of the party in the minority. In this respect, corporate elites as a group are more like individual donors and less like lobbyists and corporate PACs.

18 Unlike corporate PACs, lobbyists are shown to be highly ideological. This finding is consistent with Koger and Victor (2009). 


\section{Bipartisan boardrooms}

Corporate America is commonly viewed as a conservative stronghold. Although widely accepted by many as common knowledge, this claim is largely untested. The contribution records of corporate elites offer one way to address to this claim. Again, the measures of donor ideology are the common-space DIME scores, which allow for direct comparisons between corporate elites, candidates, and other groups of donors. ${ }^{19}$

Figure 5 shows how the ideal point distribution for the Fortune 500 sample compares with the distributions for members of Congress and the donor population at large. To help interpret the liberal to conservative scale, the figure displays the names and ideological positions of several well-known politicians as reference points. The population of Fortune 500 donors skews to the right but remains

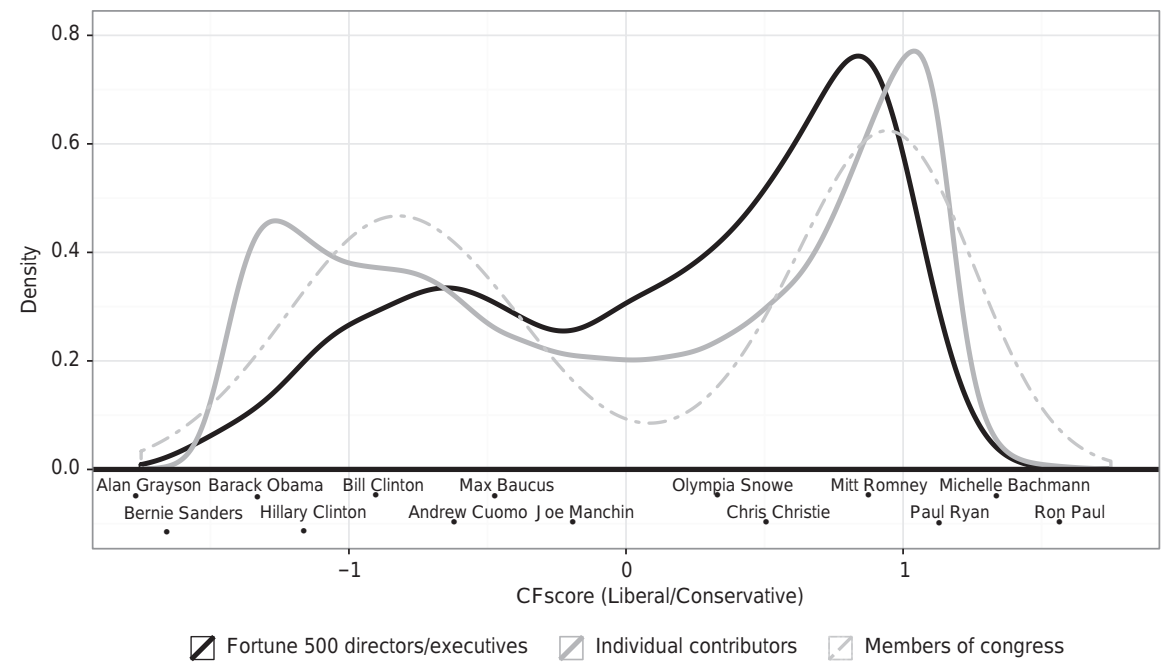

Figure 5: Comparison of ideological distributions of candidates, individual donors, and Fortune 500 directors and executives.

Source: Author's calculations using DIME scores, as described in Bonica (2014), as measures of donor ideology. Data on political contributions from the Database on Ideology, Money in Politics, and Elections.

Note: The names below the density plots are the ideological positions of several well known politicians, which are included to help in interpreting the scale.

19 In Supplementary material E, I show that the DIME scores are nearly identical to ideal points recovered by the reduced form IRT model that controls for non-spatial covariates. 
relatively balanced overall. The median position of Fortune 500 donors is 0.33 , which is in the vicinity of Olympia Snowe and Chris Christie, as compared to a median of 0.07 for the population of individual donors.

Figure 6 surveys the board room ideology from the 30 largest corporations as measured by revenue in 2012. Each line plots the ideological estimates for a corporation's CEO and each of its directors. The points indicate ideological positions of individuals within the firm and are log-scaled with respect to the total amounts contributed. Although board members from some sectors are more concentrated on the right (as is the case for the oil, gas, and coal industries), most corporate boards are ideologically heterogeneous. Finding that members of the same board give to candidates with opposed policy views suggests that their personal preferences, rather than the interests of their firms, largely dictate which candidates they support. Indeed, reconciling the result with the notion that corporate elites give primarily to promote the interests of their firms or the claim that the observed ideological consistency in their contribution patterns is an artifact of efforts to promote these interests would appear exceedingly difficult without also allowing for widespread disagreement within firms about which types of candidates or policies are in the firm's best interest.

One implication of ideological heterogeneity within firms is that individual board members do not need to deviate from their personal preferences to achieve partisan balance at the level of the firm. Figure 7 compares the distributions of partisan giving ratios for individual directors, directors grouped by corporation, and corporate PACs. When directors are viewed individually, the resulting distribution is more similar to that of the general population of individual donors, with a majority of observations at 0 or 1 . However, when contributions by board members are aggregated by corporation, the resulting distribution begins to more closely resemble that of corporate PACs. This result fits well with the claim that preference aggregation could have a moderating influence on firm behavior.

\section{Linking individual and firm behavior}

The strong empirical evidence in support of the three conditions set forth above establishes preference heterogeneity as a viable explanation for the limited corporate response to Citizens United. Combining the finding that ideologically homogeneous firms are quite rare among publicly held Fortune 500 firms with the fact that only two are on record for contributing to outside groups, precludes any serious attempt at empirically testing the preference aggregation hypothesis. Nonetheless, results presented here provide useful context for explaining the otherwise curious 


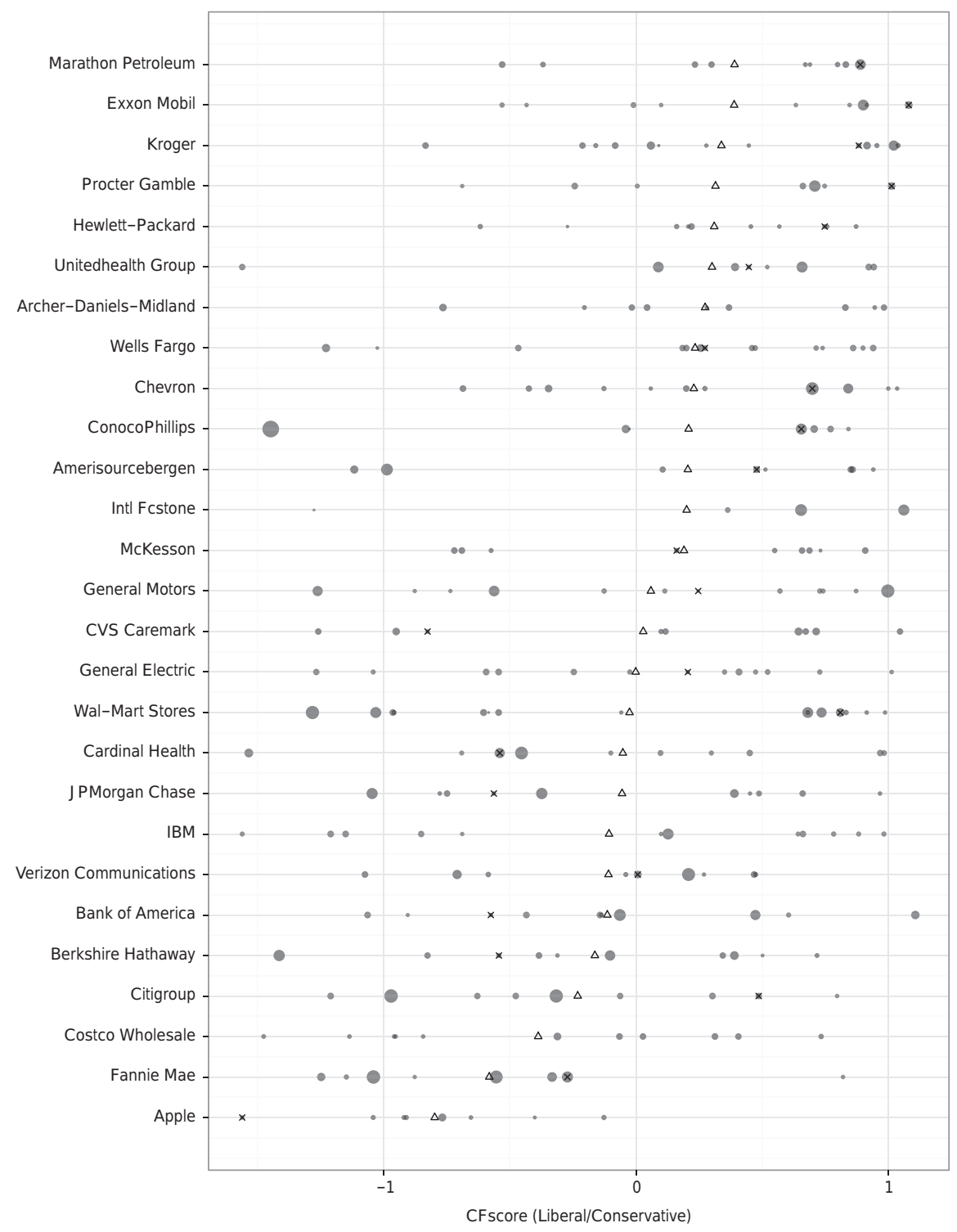

Figure 6: Corporate boardroom ideology.

Source: Database on Ideology, Money in Politics and Elections.

Note: The triangles indicate the ideal point of the median member of each corporate board. The $\times$ 's indicate the position of the positions of the CEOs. The solid gray dots indicate ideal points for board members. The point sizes are log-scaled with respect to the total amount contributed. 

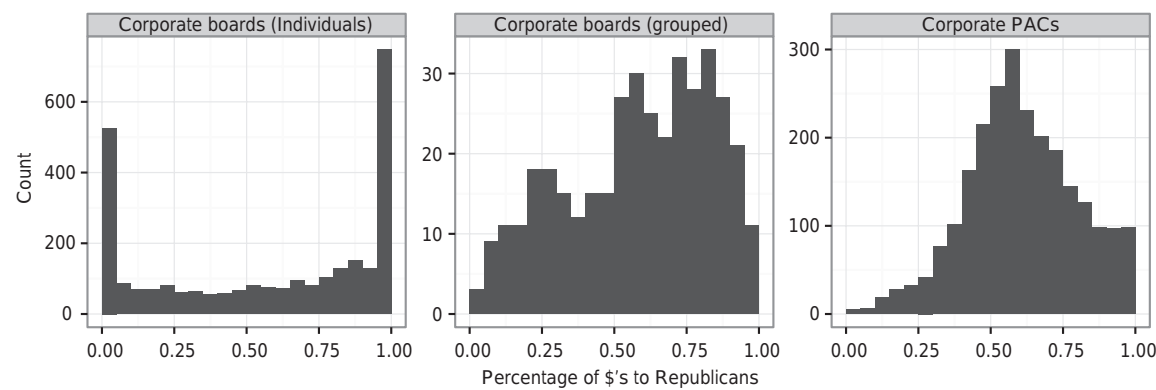

Figure 7: Partisan giving by directors, directors aggregated by firm, and corporate PACs. Source: Database on Ideology, Money in Politics, and Elections. Note: Partisan giving rates are measured as the percentage of major party contributions that go to Republicans.

lack of corporate political expenditures following the ruling in Citizens United and identifying the types of scenarios that could lead corporations to start spending big on elections if the right conditions were to arise in the future.

Partisan Agents, Bi-partisan Firms Corporations have long been reluctant to enter into the arena of partisan politics by taking sides in competitive electoral contests. Indeed, despite the natural policy inclinations of many corporations to support pro-business Republicans, corporate PACs have a long history of bipartisan giving that skews heavily to entrenched incumbents that are unlikely to face a serious challenge. ${ }^{20}$ This balanced approach to spending on politics is not shared by individual directors and executives, many of whom are intensely partisan actors. The phenomenally high rates of giving for directors suggest that political advocacy is understood as being part of the job description. Why are executives and directors not expected to behave similarly to corporate PACs?

One possibility is that allowing corporate elites to give on their own terms opens up a channel of political influence that might otherwise be off-limits to most corporations. Corporate elites acting in their capacity as individual donors may not incur the same level of risk as corporate PACs. Even if giving by corporate elites is constrained by their personal ideological preferences, they may still use the access it affords them to advocate or network on behalf of themselves and their firms. As a result, a likely byproduct of the ideological heterogeneity of corporate elites is to ensure that firms remain well connected in both parties. ${ }^{21}$

Alternatively, the political preferences of corporate elites might constrain how firms spend on politics rather than the other way around. There are good

20 Snyder (1990, 1992).

21 Bonica et al. (2013). 
reasons to doubt the ability of a group of key decision-makers who are dispersed across the ideological spectrum to coordinate on a partisan political strategy. Deciding which candidates to support could prove contentious for boards with strong contingents of both liberals and conservatives. Even if a clear majority agrees that supporting a certain candidate or party is in the interest of the firm, doing so might risk upsetting or alienating other board members. It just might not make sense for ideological factions within a firm to take sides when it comes to partisan politics when they could easily compromise on not spending the money or allocating it to lobbying or the type of non-partisan issue ads that were already common before Citizens United. Simply put, bipartisan boards might be less compatible with partisan politics.

Who has authority over corporate political expenditures? Although the set of actors with control over political expenditures is not always readily ascertainable and varies by firm, boards typically have some role in the decision process. It is increasingly common for boards to have official oversight capacity. According to the 2014 CPA-Zicklin Index of Corporate Political Disclosure, 65 percent of major corporations have regular board oversight of political expenditures, up from just 23 percent in 2010, with 15 percent requiring board approval for all political expenditures. The percentage of companies with regular board oversight of political expenditures is even greater among the 100 largest firms by market cap at 88 percent.

There is also the issue of how preferences of relevant actors are weighted. Firm-wide decisions, especially those with political implications, are likely dispersed at most corporations but may be more concentrated in others. In the extreme case, a single individual might rule with near dictatorial power. Absent the need to aggregate preferences across multiple actors, such firms could be thought of as perfectly homogeneous. There is some evidence that firms where power is highly concentrated are more likely to make political expenditures. Each of the top three corporations to spend on independent expenditures during the 2012 election cycle - Oxbow, Contran, and Crow Holdings - is a privately held corporation controlled by a major Republican donor - William Koch, Harold Simmons, and Trammel Crow, respectively - with a history of donating millions from their personal accounts. This observation, although anecdotal, is consistent with the preference aggregation hypothesis.

Is within-firm heterogeneity a function of political incentives? The best practices of corporate governance typically identify sophistication or industry expertise as the key criteria to consider when selecting directors. It is no secret, however, that corporations often value directors because of whom they know rather than what they know. Ex-politicians are commonplace on corporate boards. Palmer and Schneer (2016) report that since 1992, 47 percent of former 
senators have sat on the boards of one or more publicly traded corporation. This strongly suggests that politics factor into recruitment decisions. Nonetheless, valuing political connections is not the same as valuing ideological diversity.

There are two scenarios that could explain the observed within-firm heterogeneity. This first is that directors are selected for reasons unrelated to ideology and, as a result, the distribution of directors reflects the underlying ideological distribution of the pool of potential directors. Alternatively, the observed heterogeneity could be by design. If shareholders and others involved in the selection of board members view ideological diversity as desirable, they may factor in the personal ideology of candidates when searching for new directors. Companies may face pressure to correct for imbalances if its board starts to tilt too far to the left or right, not unlike pressures to correct for gender imbalances. If this second scenario widely holds, the relationship between within-firm ideological heterogeneity and corporations' aversion to independent expenditures could both result from outside pressures.

Absent any evidence that directors are selected with achieving partisan balance in mind, the first scenario seems much more plausible, if only because it would be expected to emerge naturally. While there have been public campaigns calling for increased diversity on corporate boards, none has focused on increasing ideological diversity.

What makes corporations different? One puzzle left unexplained is why corporations behave so differently from other types of organizations. Labor unions, which presumably have just as much riding on policy outcomes, offer the starkest contrast to corporations. The constrasting strategies of labor and corporate PACs is widely accepted as a stylized fact about American politics. ${ }^{22}$ Unlike corporations, labor unions do not shy away from electioneering and have fully embraced independent expenditures following the ruling in Citizens United. Yet many of the same arguments for why corporations adopt risk-averse, electorally neutral political strategies would also seem to apply to labor unions. Similar to the risks corporations face in alienating consumers, unions risk alienating duespaying members who are Republicans. Moreover, the de facto alliance between labor and Democrats creates partisan incentives for Republicans to step beyond opposing unions on policy matters to actively promoting policies designed to weaken unions and, in turn, the Democratic Party. ${ }^{23}$

One way in which unions appear to differ from corporations is the level of ideological diversity among key decision-makers. I collected data on the political

22 Snyder (1992).

23 Anzia and Moe (2014). 
contributions of members of the executive councils for five of the nation's largest unions. ${ }^{24}$ Union leaders are nearly as active political donors as corporate executives, although they tend to give in more modest amounts. The data reveal leaders at large unions to be ideologically homogeneous both within and across organizations. Of the 35 executive members in the sample, none is on record as having ever donated to a Republican. Although merely suggestive, organized labor's immediate adoption of independent expenditures does appear to fit with the preference aggregation account.

Of course, the comparison between corporations and unions can only be taken so far. They are fundamentally different types of institutions that serve very different purposes. Nonetheless, labor unions might offer a promising path forward for research on how preference aggregation shapes the political strategies of institutions. Unlike corporations, there is significant variation of independent expenditure amounts across unions. If leaders of some unions - perhaps public safety unions and trade unions - exhibit greater ideological diversity, it might allow for an empirical test of the preference aggregation hypothesis.

The above offers potential insights into the types of scenarios that could lead corporations to start spending on elections if the right conditions were to arise. The increasingly hostile relationship between the oil, gas, and coal industry and the Democratic Party foreshadow what such a scenario might look like. If the oil, gas, and coal industry's relationship with Republicans begins to more closely resemble organized labor's relationship with Democrats, firms with ideologically cohesive management structure may spend aggressively if they believe the Democratic party or presidential candidate is antithetical to their interests. Even so, it not yet clear whether such a strategy would yield greater returns than continued lobbying efforts. What is clear is that, as of yet, no large corporation has adopted such a strategy.

\section{Conclusions and future research}

The continuing debate over campaign finance reform stands to benefit from a more sophisticated understanding of the ways in which corporations seek to influence policy. Corporate political influence seldom arises from the avenues that receive the greatest scrutiny. In a careful accounting of corporate political expenditures, I find little evidence that the ruling in Citizens United has had any practical effect on

24 The list includes The United Automobile Workers, The National Education Association, The United Steelworkers, The International Association of Machinists and Aerospace Workers, and The International Brotherhood of Teamsters. 
how corporations spend on politics. This implies that independent expenditures are either underutilized or simply not seen as viable mechanisms for corporations to exert much influence. The amounts spent on lobbying the federal government suggests that access, rather than spending to influence elections, is the primary means by which corporations influence policy in their favor.

As individual donors with interests that align closely with corporations, corporate elites present a interesting case for studying how donors with competing incentives balance between them. I have shown that corporate elites are very active in the political marketplace and behave very differently from corporate PACs. Corporate elites are more ideological and are more willing to direct funds to non-incumbents and competitive races and far less likely to favor candidates in positions of power. The findings speak to the wider literature on campaign finance by demonstrating that theoretical models developed with corporate and special interest PACs in mind are a poor fit for corporate elites.

This study is the first to document ideological heterogeneity within and across firms and to consider how aggregation of political preferences of key actors within firms might shape corporate political strategies. In doing so, it provides a novel explanation and supporting evidence as to why corporations abstained from spending on politics through the channels opened up to them by the ruling in Citizens United. One limitation of this study is that it does not attempt to fully resolve which types of actors within a firm determine political strategies or how this might vary across firms. It also does not consider the role of governmental relations departments, which may be granted considerable discretion in determining political strategies at some firms. This along with an investigation of how the variation in the ideological heterogeneity among leaders of labor unions and other organizations explains political strategies are promising avenues for future research. Both are positioned to provide further insights into whether the ideological diversity of corporate elites is in fact an additional barrier that protects citizens from corporate funded elections.

Acknowledgments: I thank Namir Shah and Enrikson Eugenio for their assistance in compiling the dataset. I would also like to acknowledge the generous support of the Institute for Research in the Social Sciences (IRiSS) and the Hoover Institution.

\section{References}

Ansolabehere, Stephen, John M. de Figueiredo, and James M. Snyder. 2003. "Why is There so Little Money in U.S. Politics?” Journal of Economic Perspectives 17: 105-130. 
Anzia, Sarah F., and Terry M. Moe. 2014. "Public Sector Unions and the Costs of Government." Journal of Politics, Forthcoming.

Bonica, Adam. 2013a. "Database on Ideology, Money in Politics, and Elections: Public Version 1.0 [computer File].".

Bonica, Adam. 2013b. "Ideology and Interests in the Political Marketplace." American Journal of Political Science 57 (2): 294-311.

Bonica, Adam. 2014. “Mapping the Ideological Marketplace.” American Journal of Political Science 58 (2): 367-387.

Bonica, Adam, Nolan McCarty, Keith T. Poole, and Howard Rosenthal. 2013. "Why Hasn'T Democracy Slowed Rising Inequality?” The Journal of Economic Perspectives 27 (3): 103-123.

Burris, Val. 2001. "The Two Faces of Capital: Corporations and Individual Capitalists as Political Actors." American Sociological Review 66 (3): 361-381.

Busch, Marc L., and Eric Reinhardt. 2000. "Geography, International Trade, and Political Mobilization in U.S. Industries.” American Journal of Political Science 44 (4): 703-719.

Cameron, Adrian C., and Frank A. G. Windmeijer. 1996. "R-Squared Measures for Count Data Regression Models with Applications to Health-Care Utilization." Journal of Business \& Economic Statistics 14: 209-220.

Chin, M. K., Donald C. Hambrick, and Linda K. Treviño. 2013. "Political Ideologies of Ceos the Influence of Executives' Values on Corporate Social Responsibility." Administrative Science Quarterly 58 (2): 197-232.

Cox, Gary W., and Eric Magar. 1999. “How Much is Majority Status in the U.S. Congress Worth?” The American Political Science Review 93 (2): 299-309.

de Figueiredo, John M., and Brian S. Silverman. 2006. "Academic Earmarks and the Returns to Lobbying." Journal of Law and Economics 49 (2): 597-625.

Denzau, Arthur T., and Michael C. Munger. 1986. "Legislators and Interest Groups: How Unorganized Interests Get Represented.” American Political Science Review 80 (1): 89-106.

Fremeth, Adam, Brandon Schaufele, and Brian Richter. 2013. "Campaign Contributions over Ceos Careers.” American Economic Journal: Applied Economics 5 (3): 170-188.

Gordon, Sanford C., Catherine Hafer, and Dimitri Landa. 2007. "Consumption or Investment? On Motivations for Political Giving." Journal of Politics 69 (4): 1057-1072.

Hall, Richard L., and Frank W. Wayman. 1990. "Buying Time: Moneyed Interests and the Mobilization of Bian in Congressional Committees.” American Political Science Review 84: 797-820.

Koger, Gregory, and Jennifer Nicoll Victor. 2009. "Polarized Agents: Campaign Contributions by Lobbyists.” PS: Political Science and Politics 42: 485-488.

Langbein, Laura I. 1986. "Money and Access: Some Empirical Evidence." The Journal of Politics 48 (4): 1052-1062.

Milyo, J., D. Primo, and T. Groseclose. 2000. “Corporate PAC Campaign Contributions in Perspective." Business and Politics 2 (1): 75-88.

Ovtchinnikov, Alexei V., and Eva Pantaleoni. 2012. "Individual Political Contributions and Firm Performance." Journal of Financial Economics 105 (2): 367-392.

Palmer, Maxwell, and Benjamin Schneer. 2016. "Capitol Gains: The Returns to Elected Office from Corporate Board Directorships.” The Journal of Politics 78 (1): 181-196.

Snyder, James M. Jr. 1990. "Campaign Contributions as Investments: The U.S. House of Representatives, 1980-1986.” Journal of Political Economy 98 (6): 1195-1227. 
Snyder, James M. Jr. 1992. "Long-Term Investing in Politicians; or, Give Early, Give Often.” Journal of Law and Economics 35 (1): 15-43.

Tullock, Gordon. 1972. "The Purchase of Politicians.” Western Economic Journal 10 (3): 354-355. Welch, W. P. 1980. "The Allocation of Political Monies: Economic Interest Groups." Public Choice 35 (1): 97-120.

Supplemental Material: The online version of this article (DOI: 10.1515/bap-2016-0004) offers supplementary material, available to authorized users. 